\title{
Fiscal Restraints and Voter Welfare
}

\author{
Timothy Besley \\ London School of Economics \\ London WC2A $2 \mathrm{AE}$ \\ Michael Smart \\ University of Toronto \\ Toronto ON M5S 3G7 Canada
}

PEPP/6

July 2005
Political Economy and Public Policy Series The Suntory Centre

Suntory and Toyota International Centres for Economics and Related Disciplines

London School of Economics and Political Science Houghton Street

London WC2A 2AE

Tel: (020) 79556674

(C) The author. All rights reserved. Short sections of text, not to exceed two paragraphs, may be quoted without explicit permission provided that full credit, including $\mathbb{C}$ notice, is given to the source 


\title{
Fiscal Restraints and Voter Welfare*
}

\author{
Timothy Besley \\ London School of Economics \\ London WC2A $2 \mathrm{AE}$ \\ Michael Smart \\ University of Toronto \\ Toronto ON M5S 3G7 Canada
}

July 2005

\begin{abstract}
This paper explores the logic of fiscal restraints in a political agency model with both moral hazard and adverse selection. The role of the political process is both to discipline incumbents who may act against the public interest and to sort in those politicians who are most likely act in voters' interests. We use the model to examine the optimality of inefficient taxation, limits on the size of government, increasing transparency, and yardstick competition. Some conclusions are surprising. For example, we show that some forms of fiscal restraint can only be desirable when incumbents are sufficiently likely to be benevolent.
\end{abstract}

${ }^{*}$ We are grateful to Jim Hines and a number of seminar participants for insightful comments. 


\section{Introduction}

There are two important normative traditions in modern public finance theory. On one side is the Pigouvian tradition which looks at the structure of government from the perspective of a benevolent social planner. ${ }^{1}$ On the other is the Public Choice tradition, especially the work of James Buchanan, in which the optimal scope and structure of government is derived on the assumption that government is populated by rationally self-interested actors who may use the state to further their private ends. ${ }^{2}$ A defining difference between these traditions can be seen in their attitude towards efficient taxation. The Pigouvian tradition unambiguously applauds efficient taxes. However, the Public Choice tradition is more circumspect, even suggesting that strategic inefficiencies in revenue collection can raise welfare by acting as a restraint on government.

This paper explores the logic of this argument in a political agency model with both moral hazard and adverse selection. From this perspective, the political process serves both to discipline incumbents who may act against the public interest and to sort in those politicians who are most likely act in this way.

The model generates some surprising insights about the optimality of restraints on government. For example, inefficient taxation is never optimal for voters when most politicians act solely for private gain; sufficiently many Pigouvian politicians are required for the conclusions of the Public Choice school to survive in our model.

The logic of our argument can be seen in the following example. Consider a world in which politicians may be either corrupt or honest, and corrupt officeholders can escape detection and remain in office, as long as their corrupt activities are not too egregious. Suppose then that auditing technologies in government improved to the point that all corruption could be detected and revealed to voters, but not until after the fact. If corrupt politicians are indeed motivated only by private gain, their rational response must be

\footnotetext{
${ }^{1}$ In fact Pigou recognized the potential failings of the state. He notes that "(i)t is not sufficient to contrast the imperfect adjustments of unfettered enterprise with the best adjustment that economists in their studies can imagine. For we cannot expect that any State authority will attain, or will even whole-heartedly seek, that ideal. Such authorities are liable alike to ignorance, to sectional pressure and to personal corruption by private interest." Pigou (1920, p. 296).

${ }^{2}$ See, for example, Buchanan $(1967,1989)$.
} 
to increase rent extraction before leaving office. Thus corruption among first-term incumbents would inevitably rise, but fewer corrupt politicians would remain in office, leading to an ambiguous effect on the average level of corruption.

Having established the trade-off between discipline and selection in the case of inefficient taxation, we then use the model to explore a variety of other measures aimed at restraining government, namely greater transparency in decision making, yardstick competition, and limits on the size of government. From analysis of these various institutions, a general way of thinking about the issues emerges. The effects of fiscal restraints can be decomposed into two key elements - direct consequences of the constraints faced by incumbent politicians and indirect consequences via changes in the political equilibrium. The direct effects tend to be straightforward. However, the indirect effects are more surprising and drive the conclusions. But since the reason that these restraints are being considered in the first place are "failures" in the political process, they are also the part that merits attention.

More generally, the results can be seen as a political theory of the second best also emphasized by Fischer and Summers (1989). Agency problems in government are only partially resolved by having open elections. Since residual problems remain, a further distortion in the form of inefficient taxation can be welfare enhancing, or it may simply exacerbate existing problems in the political system.

The remainder of the paper is organized as follows. Section two provides some background on the literature and elaborates on the key ideas. Section three introduces the model. It characterizes equilibrium and establishes that, due to the commitment problem facing voters, improvements in voters' information may in some circumstances lead to increases in rent extraction and lower welfare. It also shows how voter welfare can be thought of in terms of selection and discipline effects. Section four uses the model to examine the effect of increasing the marginal cost of public funds. Section five extends the model to study tax limits, transparency, and yardstick competition. Section six concludes.

\section{Background}

Our political model is a version of the political agency models introduced by Barro (1973) and Ferejohn (1986), recently reviewed in Besley (2003). 
This approach captures the idea that the quality of government hinges on the ability of voters to deal with the principal agent problem that they face vis a vis public officials. Moreover, it is an approach which allows the Pigouvian model and the Public Choice models of government to be represented as limiting cases. In addition to their theoretical attractions, the central predictions of these models have received support from empirical analysis of political decision-making and voter behavior. For example, Peltzman (1992) found that voters respond negatively to spending increases at the state and federal levels in the U.S. Besley and Case (1995a) showed that voters in gubernatorial elections evaluate incumbent performance in a rather sophisticated manner: the electoral consequence of a tax increase in one state depends on fiscal performance in neighboring states. Besley and Case (1995b) in turn provide evidence on how accountability in government responds to electoral incentives. They find that governors who face binding term limits choose tax and expenditure policies that differ from those who do not.

This paper is related to previous work linking efficient taxation and policy outcomes. In one important contribution, Becker and Mulligan (1998) consider how changing the efficiency of the tax system alters the resources devoted to political influence. If greater deadweight cost in the tax system leads to reductions in influence activities that more than offset the direct costs to taxpayers then it can be good from a societal point of view. Krusell, Quadrini and Rios-Rull (1996) argue that income taxation can be attractive relative to consumption taxation even when the latter has less deadweight loss since it leads to a lower level of transfer activity in equilibrium. Our political model differs from those employed in previous papers on this issue. One virtue of our approach is showing how the case for efficient taxation depends on whether the political system is closer to the Pigouvian or Public Choice world.

Whether to introduce formal limits on the size of government is a staple issue of the public choice literature. The case for this has been made forcefully by Brennan and Buchanan (1980). However, they study the issue using the Leviathan model in which governments seek to maximize the size of the public sector and electoral pressures serve no role in curbing behavior. A number of U.S. states have adopted measures which curb the growth of government by limiting taxes (see Rueben (1997)). This is premised on some weakness in the electoral process which prevents normal electoral channels from effectively representing voter interests.

The main ideas apply to thinking about the importance of transparency 
in government. ${ }^{3} \quad$ Greater transparency can reduce the incentives for bad politicians to try to convince voters that they are good since they are more likely to be found out when pursuing such strategies. Thus, increased transparency can actually lead to worse incumbent discipline. The flip side of this is better selection, as bad politicians are more often "found out". The balance of these selection and incentive effects determine whether greater information provision is good for voters. ${ }^{4}$

The approach also casts light on debates about the value of competitive governments. There are two main dimensions. First, we show that the results on inefficient taxation can be interpreted in light of concerns about competition for mobile tax bases which raise the marginal cost of public funds. Pigouvians see tax competition as a source of welfare-decreasing externalities between governments, while the Public Choice tradition applauds the possibility that competition of this form can restrain the use of government as a private interest. ${ }^{5}$ Our model casts light on whether competition that raises the marginal cost of public funds is desirable. ${ }^{6}$

\footnotetext{
${ }^{3}$ Transparency is one among a variety of budgetary institutions which have concerned analysts - see Poterba and von Hagen (1999) for a variety of studies. Alt and Dreyer Lassen (2003) demonstrates the empirical relevance of fiscal transparency in OECD countries.

${ }^{4}$ Prat (2002) and Dewatripont, Jewitt and Tirole (1999) also consider the value of information in agency models without commitment. They also show that less information for principals may be sometimes be better.

${ }^{5}$ In debates about the role of tax competition, the Leviathan model of government due to Brennan and Buchanan (1980) has played a key role. This model is based on the notion that government would seek to maximize the tax revenues extracted from its citizens. Moreover, because citizens find it difficult to control the behavior of (self-interested) officials, government spending and tax rates tend to exceed efficient levels. By creating downward pressure on tax rates, then, tax competition may supplement the limited constitutional means available to taxpayers to constrain their political leaders. This argument was further explored in Edwards and Keen (1996). Wilson (2000) provides an alternative model in which competition can induce greater public spending to attract mobile capital if the latter raises the productivity of capital located in a particular jurisdiction.

${ }^{6}$ Sorting out the welfare consequences of intergovernmental competition is of more than academic interest. The received wisdom is that increased economic integration among nations in recent years has increased the mobility of tax bases across national borders, with "tax competition" among governments attempting to attract mobile tax basesparticularly capital income - by lowering rates below efficient levels. In response to this OECD (1998) developed guidelines for eliminating "harmful tax competition" among member nations. However, the report contained a dissenting appendix by the government of Switzerland arguing that "competition in tax matters ... discourages governments from
} 
Our model also has implications for the value of inter-governmental yardstick competition, which was first discussed in the context of governments by Salmon (1987) and its empirical relevance established in Besley and Case (1995a). ${ }^{7}$ Increasingly, public spending functions in a number of countries are being decentralized to local governments and agencies. Decentralization is motivated in part by a desire to generate performance comparisons among decision-makers and so to enhance incentives for efficient provision of public services. Our analysis shows that whether such yardstick competition is welfare improving also depends on how it affects the balance of discipline and selection effects in government.

\section{The model}

Government and the economy. We study an agency model of elections with two time periods; in each, the politician in office makes decisions about government spending. Between periods, there is an election in which a voter chooses between the incumbent and a challenger. Specifically, in each period, the politician observes the unit $\operatorname{cost} \theta$ of providing a public good and then unilaterally chooses the quantity of the good provided $G$ and the amount of rent diversion for private purposes, or "waste," $s$. Total government spending for the period (equal to tax collections) is then $x=\theta G+s$. The cost of the public good is independently and identically distributed in each period, with $\theta \in\{L, H\}, H>L$, and $\operatorname{Pr}(\theta=H)=q$. The representative voter derives utility from public goods, net of the cost of government spending. When the politician provides public goods in the amount $G$ and total spending is $x$, the welfare of the voter is $W(G, x)=G-\mu C(x)$, where $C$ is a strictly convex, increasing function and $\mu$ is an exogenous parameter that indexes the marginal cost of public funds in a simple way.

Politicians may be one of two types, "good" or "bad". Thus we label the politician's type by $i \in\{b, g\}$. A good politician simply chooses $G$ in each period to maximize voter welfare, and places no value on rents diverted from

adopting confiscatory fiscal regimes, which hamper entrepreneurial spirit and hurt the economy, and it avoids alignment of tax burdens at the highest level." (p. 77) The recent OECD stance has softened - with initiatives aimed more at eliminating "harmful tax practices" - the stance on tax competition is more agnostic.

${ }^{7}$ The theory of yardstick competition is also studied in Bordignon et al (2001), Hindriks and Belleflamme (2001) and Bodenstein and Ursprung (2001). 
public spending. Given $\theta$, therefore, the level of public goods provided by the good politician is

$$
G^{*}(\theta, \mu)=\arg \max G-\mu C(\theta G)
$$

We denote the associated level of spending by $x_{\theta}=\theta G^{*}(\theta, \mu)$ and of voter welfare by $W^{g}(\theta, \mu)$. Evidently, $G^{*}$ and $W^{g}$ are decreasing in $\mu$.

In contrast, a bad politician behaves strategically, choosing policies to maximize the expected, discounted sum of rents $s_{1}+\beta \sigma s_{2}$ extracted from government, where $\beta<1$ is a discount factor, and $\sigma$ is the probability of re-election to second term. We assume that there is a maximal feasible level of government tax collections; thus $x \in[0, X]$, where $X \geq x_{L}$. The determination of the re-election rule is discussed below.

Information and Timing. The types $i \in\{g, b\}$ of first-period incumbent and challenger are independent draws from an identical distribution with $\operatorname{Pr}(i=g)=\pi$. The incumbent then observes the first-period cost shock $\theta$ and chooses public goods provision $G$ and rent diversion $s$. The voter then observes $G$ and government spending $x$ prior to the election at the end of the first period. However, the types of incumbent and challenger, the unit cost $\theta$, and the level of rent diversion $s$ are unobserved. In the second period, the politician then in office again chooses $G$ and $s$ given $\theta$. There are no further elections; thus even newly elected challengers are "lame ducks" in the second period. In casting their votes in the election, therefore, the voter must make an inference about the incumbent's type based on observed performance and compare it to prior beliefs about the type of the challenger.

In this framework, elections serve a role in selecting good incumbents for re-election in the second period. Moreover, as we shall see, elections may also provide incentives for bad first-period incumbents to restrain waste in government, in the hope of being mistaken for a good politician and being re-elected to a second term. For two reasons, however, the equilibrium outcomes depart from those associated with an optimal incentive contract for politicians. First, feasible contracts are restricted - they are confined to the voter's binary choice of re-election, rather than a general pay-for-performance contract. Second, the voter faces a commitment problem - they cast their votes for re-election after first-period spending decisions have been made. It follows that the equilibrium re-election rule is chosen to select politicians optimally ex post, but it will not provide the efficient degree of ex ante incentives. If it were possible, the voter might wish to commit to a relatively 
tough re-election rule that removed even fairly good incumbents from office "pour encourager les autres". However, in this model, such a rule would not be credible and would, therefore, have no impact on incentives.

\subsection{Equilibrium}

The foregoing structure defines a game of incomplete information between the incumbent politician and the representative voter. We seek to characterize perfect Bayesian equilibria of this game. As usual, the game is most easily solved by applying a type of backward induction. In the second period, the politician in office faces no further possibility of electoral discipline. Thus $s_{2}=X$ for $i=b$ (bad politicians take maximal rents) while $s_{2}=0$ for $i=g$. Given $s_{2}$, the politician chooses $G$ to maximize voter welfare.

Given that second-period strategies are identical for challenger and incumbent, the sequentially rational voting rule for the voter is to re-elect the incumbent if the posterior probability the incumbent is the good type exceeds the prior probability $\pi$ that the challenger is good. The voter's posterior beliefs depend in turn on the equilibrium strategy of the first-period incumbent. Since the good type cares only about voter welfare in the current period, he chooses $\left(G_{H}^{*}, x_{H}\right)$ with probability $q$ and $\left(G_{L}^{*}, x_{L}\right)$ with probability $1-q$. It follows that, in any perfect Bayesian equilibrium, the voter's posterior beliefs assign probability zero to the good type at any other information set $(G, x)$. To economize on notation, we therefore write posterior beliefs as a function $\operatorname{Pr}(g \mid x)$ of first-period spending alone. Of course, the voter's beliefs are not restricted by Bayes' rule at nodes not reached in equilibrium. Since the good type's actions are pinned down by our preference assumption, we impose the minimal restriction on out-of-equilibrium beliefs that $\operatorname{Pr}(g \mid x)=0$ if $(G, x) \neq\left(G_{\theta}^{*}, x_{\theta}\right)$ for $\theta \in\{L, H\}$. At any such information set, the voter would elect the challenger in the second period.

Accordingly, we can confine attention to three possible strategies for the bad incumbent, each associated with one of the three spending levels $\left(x_{L}, x_{H}, X\right)$ that are observed with positive probability on the equilibrium path. First, $b$ might choose $s_{1}=0$ or $s_{1}=X$. Since future rents are discounted $(\beta<1)$, however, the latter strategy dominates the former. ${ }^{8}$ Thus

$$
\operatorname{Pr}\left(g \mid x_{L}\right)=1
$$

\footnotetext{
${ }^{8}$ Regardless of true costs, $s_{1}=0$ yields a payoff to the bad type of $\beta X$ if re-elected and zero otherwise, while $s_{1}=X$ pays $(1+\beta) X$ if re-elected and $X$ otherwise.
} 
in any equilibrium, and the voter always re-elects when first-period spending is $x_{L}$. Beliefs conditional on observing $x_{H}$ are more complicated. A bad politician who faces low true costs may, instead of taking maximal rents, choose to produce $G_{H}^{*}$ units of the public good and spend $x_{H}$, diverting $\hat{s}(\mu) \equiv(H-L) G^{*}(H, \mu)$ to private rent consumption. This strategy allows type $(b, L)$ to "pool" with type $(g, H)$, and doing so may be desirable, if it brings a positive probability of re-election. Accordingly, let

$$
\lambda=\operatorname{Pr}\left(x=x_{H} \mid \theta=L, i=b\right)
$$

denote the probability type $(b, L)$ exercises restraint in this sense, and let $\sigma$ denote the probability of re-election when the voter observes $x_{H}$. The posterior probability that spending $x_{H}$ was generated by a good politician is

$$
\operatorname{Pr}\left(g \mid x_{H}\right)=\frac{\pi q}{\pi q+(1-\pi)(1-q) \lambda}
$$

A best response for the voter is to re-elect with positive probability $(\sigma>0)$ only if $\operatorname{Pr}\left(g \mid x_{H}\right) \geq \pi$ or, equivalently, $\lambda \leq q /(1-q)$. If the inequality is strict, then $\sigma=1$. Further, type $(b, L)$ prefers to exercise restraint instead of diverting maximal rents $(\lambda>0)$, only if $\hat{s}+\beta \sigma X \geq X$. When this inequality is strict, then $\lambda=1$.

Collecting these observations, there are three possible equilibrium configurations. First, equilibrium may be pooling, as type $(b, L)$ chooses $s_{1}=\hat{s}$ and so is indistinguishable from type $(g, H)$. Second, equilibrium may be separating, as type $(b, L)$ chooses $s_{1}=X$ and is revealed ex post. Third, equilibrium may be a hybrid one, in which type $(b, L)$ adopts a strictly mixed strategy on actions $s_{1}=\hat{s}$ and $s_{1}=X$, so that type is revealed with positive probability strictly less than one. The following result fully characterizes the possible configurations.

Lemma 1 An equilibrium exists for all values of parameters and is generically unique.

1. A pooling equilibrium, with $\lambda=\sigma=1$, exists if and only if

$$
q \geq \frac{1}{2} \& \hat{s}(\mu) \geq(1-\beta) X
$$


2. A hybrid equilibrium, with $\lambda=q /(1-q)$ and $\sigma=(X-\hat{s}) /(\beta X)$, exists if and only if

$$
q<\frac{1}{2} \& \hat{s}(\mu) \geq(1-\beta) X
$$

3. A separating equilibrium, with $\lambda=0$ and $\sigma=1$, exists if and only if

$$
\hat{s}(\mu) \leq(1-\beta) X
$$

In the separating equilibrium, $b$ takes maximal rents and is detected with certainty and replaced by the challenger. (This equilibrium outcome is therefore equivalent to that which would obtain if voter could observe the cost shock directly.) In the pooling and hybrid equilibria, the incumbent is taking less than maximal rents and his type of revealed with lower probability. ${ }^{9}$ The latter is most likely when $\hat{s}(\mu)$ is high and the incumbent discounts the future a great deal so that he prizes rents earned in period one.

This framework implies a somewhat more optimistic view of politics than is standard in the Public Choice tradition - it allows for the existence of public-spirited as well as venal politicians. Even a very small fraction of good politicians can have a large effect on equilibrium behavior with sufficient discounting: if $\hat{s}(\mu) \geq(1-\beta) X$, it becomes optimal for a bad politician to mimic a good one to gain some chance of re-election. It is only when both good and bad politicians are present in the population of candidates, however, that the re-election incentive becomes credible, i.e., are part of the equilibrium behavior of the electorate.

\subsection{Selection and Incentives}

To understand how the electoral process affects political decision-making in the model, it is useful to calculate expected voter welfare in equilibrium. As a benchmark for the analysis, suppose that politicians are removed from office each period with certainty. Expected voter welfare when type $g$ is in office would then be $E W^{g}=q W_{H}^{g}+(1-q) W_{L}^{g}$, whereas welfare with $b$ in office would simply be $W^{b}=-\mu C(X)$, since "lame-duck" bad politicians divert maximal rents. To simplify notation, let $W^{0}(\mu)=\pi E W^{g}(\mu)+(1-\pi) W^{b}(\mu)$

\footnotetext{
${ }^{9}$ Note however that in the pooling equilibrium the outcome is similar to that assumed in the Leviathan model of the Public Choice tradition, where rents are often assumed to be positively related to the level of "legitimate" public spending.
} 
be the unconditional expected per-period welfare in this case. It follows that the present value of expected welfare is just $(1+\beta) W^{0}(\mu)$ when there is no chance of re-election.

Equilibrium welfare in the equilibrium described in Lemma 1 can be written as

$$
E W(\lambda, \sigma, \mu)=(1+\beta) W^{0}(\mu)+(1-\pi)(1-q) \lambda D(\mu)+\beta\left(\pi_{2}-\pi\right) S(\mu)
$$

where:

$$
\begin{gathered}
D(\mu)=W^{g}(H, \mu)-W^{b}(\mu) \\
S(\mu)=E W^{g}(\mu)-W^{b}(\mu)
\end{gathered}
$$

and

$$
\pi_{2}-\pi=\pi(1-\pi)[q \sigma+(1-q)(1-\sigma \lambda)]
$$

Equation (5) has a simple interpretation, as the last two terms represent the deviation from welfare in the absence of re-election possibilities. The term $D(\mu)$ is the discipline effect induced by re-election possibilities - the fact that bad incumbents restrain rent seeking - while $S(\mu)$ represents selection - the fact that elections improve the quality of period two policy by weeding out bad incumbents. Multiplying each effect is the probability that the relevant events occur and these benefits of elections are reaped. With probability $(1-\pi)(1-q) \lambda$, the first-period incumbent chooses to produce $G_{H}^{*}$ of the public good and divert rents $\hat{s}$ instead of $X$, resulting in the welfare gain from "discipline". The expression $\pi_{2}-\pi$ is in turn the increased confidence that the period two incumbent is good. ${ }^{10}$

In summary, the possibility of re-electing incumbents can increase voter welfare both by improving average quality of office-holders (the "selection effect") and by offering prospective incentives for low-quality incumbents (the "discipline effect"). To understand the impact of changes in the fiscal regime, the effects on selection and incentives in elections must be understood. This in turn requires understanding how equilibrium political behavior (as represented by $\lambda$ and $\sigma$ ) is affected.

\footnotetext{
${ }^{10}$ To interpret this expression, observe that the probability of Type I and Type II errors in voter's re-election decision, given the equilibrium strategies, are given by

$$
\begin{aligned}
& \tilde{\alpha}(\lambda, \sigma) \equiv \operatorname{Pr}(\text { re-elect } \mid b)=(1-q) \lambda \sigma \\
& \tilde{\beta}(\lambda, \sigma) \equiv \operatorname{Pr}(\text { do not re-elect } \mid g)=q(1-\sigma)
\end{aligned}
$$

so that $\pi_{2}-\pi=\pi(1-\pi)(1-\tilde{\alpha}-\tilde{\beta})$.
} 


\section{The Case for Inefficient Taxation}

We now turn to the effect of tax efficiency on voter welfare. The comparative static that we perform could be interpreted in one of four ways: (i) an intensification of tax competition (ii) passage of a citizens' initiative which restricts the use of a specific tax instrument (iii) passage of a constitutional restriction which restricts the tax base (iv) technological change in the ability to collect taxes. ${ }^{11}$ In all four cases, we expect the cost of public funds to change.

We now consider how an increase in the marginal cost of public funds changes voter welfare. Specifically, we consider an exogenous increase in the parameter $\mu$. Expected rent diversion is decreasing in $\mu$ in the pooling and hybrid equilibria, since $\hat{s}(\mu)=(H-L) G^{*}(H, \mu)$ is decreasing in $\mu$. By reducing the level of spending by benevolent governments, increasing inefficiency in the tax system restricts the amount of wasteful spending that can be undertaken by self-interested officials without fear of detection. To determine whether this effect can exceed the usual welfare cost of tax competition, we differentiate (5) to obtain the following result.

Proposition 2 Increased inefficiency in the tax system (as represented by an increase in $\mu$ ) that leaves equilibrium strategies $(\lambda, \sigma)$ unchanged reduces voter welfare, even if it reduces rent diversion by bad politicians.

This result holds in spite of the fact that increasing inefficiency of the tax system does (sometimes) lower rent extraction by bad incumbents. This fails to deliver a benefit to voters in any of the equilibria described in Lemma 1. When the equilibrium is separating, rent seeking is maximal anyway and voters would prefer to be "robbed" efficiently. Inefficiency in the tax system only increases the costs of venality. In pooling or hybrid equilibrium, tax inefficiency leads to reduced rent seeking. However, voters are worse off as the level of rent seeking is fixed by the condition that the incumbent behaves as if the high cost state has arisen. Inefficiencies in the tax system that raise the marginal cost of public funds only make the cost of funding public spending in this state larger.

The key assumption in Proposition 1 is that equilibrium strategies remain unchanged. However, this need not be so and, if it is not the case, there

\footnotetext{
${ }^{11}$ Peltzman (1980) argues that this has been important historically and in comparing developed and developing countries.
} 
are two competing effects to consider. First, the equilibrium can induce a change in strategy that leads to more information about the incumbent being revealed and, second, the rent extracted by politicians may change.

Returning to Lemma 1, it is clear that increasing inefficiencies in the tax system can lead to a move from a pooling or hybrid equilibrium to a separating equilibrium. Specifically, defining $\mu$ from $\hat{s}(\mu)=(1-\beta) X$, then for all $\mu>\mu$, there will be separation between the good and bad incumbents. This occurs because equilibrium rents are proportional to the size of government in the pooling or hybrid cases. As the size of government is reduced by greater inefficiency in the tax system, rent extraction possibilities are limited, making it more likely that a bad incumbent will "go for broke" and extract maximal rents. In this instance, all equilibrium information (about $\theta$ and the type of the politician) is revealed in equilibrium. Hence, to ascertain the welfare effects of tax competition which increases $\mu$ above $\mu$, we need to compare full information welfare with that in the equilibrium with $\mu<\mu$.

Intuitively, the impact on voter welfare of a move to separation involves a trade-off between the short-run costs of reduced discipline, and the longrun benefits that result when bad politicians reveal type and are removed from office. Computing welfare for the two cases from (5) shows that the selection effect outweighs the discipline effect, so that welfare is higher in the separating equilibrium, if and only if $\beta \pi S(\mu) \geq D(\mu)$. Our main result on the welfare effect of tax inefficiencies then follows:

Proposition 3 There exists a $\pi^{*}>0$ such that increasing the inefficiency of the tax system (as represented by an increase in $\mu$ ) unambiguously reduces voter welfare for all $\pi<\pi^{*}$. For $\pi \geq \pi^{*}$, an increase in the inefficiency of the tax system which moves the equilibrium from hybrid or pooling to separating may increase voter welfare if it induces a shift from a hybrid or pooling equilibrium towards a separating equilibrium. Moreover $\pi^{*}<1$ if $\beta$ is sufficiently close to one.

This result says that an increase in the inefficiency of the tax system can enhance voter welfare only if it leads to an increase in the ability of the voter to detect bad incumbents. This leads to some rather paradoxical implications. First, a sufficiently large increase in the cost of public funds may indeed increase equilibrium welfare, but only if the change increases the amount of wasteful spending in the first period. Voter welfare will 
be higher from improved selection when the fraction of good types in the population $\pi$ is sufficiently high. Furthermore, raising the marginal cost of funds can increase voter welfare only when the political process is closer to the benevolent government paradigm.

The political agency model used here has a pedigree in explaining patterns of taxing and spending in U.S. state level data, and proposition 2 generates further testable implications that link tax efficiency, political turnover and the size of government. First, the model predicts that increasing the marginal cost of public funds will increase political turnover as bad politicians are less likely to pool with good ones. Second, the effect on the size of government is ambiguous. This depends on the fractions of good and bad politicians in the data - the negative direct effect could be offset by a positive political equilibrium effect.

\section{Other Restraints}

The key to understanding whether it is ever optimal to use inefficient taxation rested on the balance of discipline and selection effects. We now apply these ideas to three further examples. For simplicity, we consider in this section the case where $q>1 / 2$. Lemma 1 now implies that only the separating and pooling equilibria are relevant. Which one of them arises depends only on whether exercising restraint is worthwhile for bad incumbents. The equilibrium is pooling if $\hat{s}(\mu)>(1-\beta) X$ and is separating otherwise.

\subsection{Limiting the Power to Tax}

Changing the marginal cost of public funds could be seen as a crude means of restraining waste in government - after all, it changes the behavior of good and bad incumbents alike. Consider instead a constitutional restriction on $X$, the maximum tax level that the government can levy. This has the advantage of reducing the rent seeking that a bad politician does when the state is $\theta=H$ and hence improving voter welfare (assuming that the limitation does not distort the behavior of good politicians). However, it reduces both the discipline and selection effects - since bad politicians are no longer as bad as they were previously. Overall, it is straightforward to show that a tax limitation that leaves the behavior of the good politicians unaltered and does not change the political equilibrium is welfare improving 
for the voter.

The more interesting case is where the tax limitation shifts the political equilibrium. $^{12}$ Lemma 1 makes clear why the effect of lowering $X$ is to increase the incentive of incumbents to pool, and so to make the political equilibrium less informative. This has the opposite effect to that of increasing $\mu$, the marginal cost of public funds. This suggests that a tax limitation will be attractive when selection is less important than discipline - i.e., when $\beta \pi S(\mu)<D(\mu)$. Thus, a tax limitation is more likely to be desirable when there is a predominance of self-interested politicians - when $\pi$ is small. This is more in line with the traditional Public Choice view.

Thus, we have:

Proposition 4 Suppose that a limit is imposed on the size of government (as measured by $X$ ). Then there exists a $\hat{\pi}$ such that voter welfare increases if $\pi<\hat{\pi}$.

This illustrates the subtle differences between the welfare effects of different types of fiscal restraint. It also illustrates the importance of analyzing the detailed effect of political incentives in response to the imposition of restraints.

\subsection{Fiscal Transparency}

We now consider the effect on the political equilibrium of supplying better information about government. This corresponds to an increase in fiscal transparency in the budgetary process - the voter learns more of the information that lies behind taxing and spending decisions. It is commonly thought that this will lead to an increase in voter welfare.

Suppose now that, after the incumbent has chosen $s_{1}$ and before the period one election is held, the voter may learn about the true cost of public services $\theta$. Specifically, the true value of $\theta$ is revealed with probability $\xi$; otherwise, no signal is received by the voter. The result in Lemma 1 is now modified. The payoff when a bad politician pools with a good one is $\hat{s}(\mu)+$ $(1-\xi) \beta X$ while, if he chooses to reveal his type, it is $X$. Pooling is now worthwhile if and only if $\hat{s}(\mu)>(1-(1-\xi) \beta) X$, a more stringent condition than in the absence of an informative signal (see Lemma 1). Moreover,

\footnotetext{
${ }^{12}$ Here we consider only the case where the maximum spending level $X$ remains high enough to leave the behavior of good politicians unchanged.
} 
pooling is less likely to be optimal the closer is $\xi$ to one. Indeed, if $\xi=1$, then the only possible period one equilibrium is separating. ${ }^{13}$

Better information therefore tends to reduce discipline and increase firstterm rent seeking. At the same time, however, it improves selection, as bad incumbents are less likely to survive re-election. By evaluating the trade-off between agency costs of first-term and second-term incumbents, we can assess whether such a change in the political equilibrium is worthwhile. Since $q>1 / 2$, the only comparison is between pooling $(\lambda=1)$ and separation $(\lambda=0)$. Evaluating welfare from (5) gives the difference between separating and pooling equilibrium welfare as

$$
(1-\pi)(1-q)(\beta \pi S(\mu)-D(\mu))
$$

We can therefore summarize the effects of transparency in the model by:

Proposition 5 Suppose that the voter receives an informative signal about the cost of providing public goods. The signal improves voter welfare only if the selection effect of elections dominates the discipline effect, i.e. $\beta \pi S(\mu) \geq$ $D(\mu)$.

The above expression reveals the determinants of this trade-off. The selection effect is larger, the better is the pool of incumbents ( $\pi$ close to one) and the lower the level of discounting.

This result suggests that, in political agency models, more information need not be desirable for voters. This is related to the broader theoretical literature on the value of information in agency relationships. In the standard complete contracts model of Holmstrom (1979), more information is better. Dewatripont, Jewitt and Tirole (1999) show that coarser information may sometimes be better in motivating agents in a career concerns model where incentives are implicit. This reflects a kind of second-best reasoning - with incomplete incentives, an otherwise welfare improving change (more information) may have deleterious effects on equilibrium behavior that more than offset the direct welfare impact. In our model, incentives are incomplete since the threat of not being re-elected is the only mechanism with which the voter may discipline incumbents.

\footnotetext{
${ }^{13} \mathrm{~A}$ similar argument can be made if we instead supposed that with some probablity information about whether $s_{1}$ is positive comes to light before the election.
} 


\subsection{Yardstick Competition}

Another aspect of competitive government is the use of comparisons as a benchmark - so-called "yardstick competition". ${ }^{14}$ Besley and Case (1995b) find evidence for the relevance of this model in U.S. state level data. This acts a fiscal restraint since the incumbent in one jurisdiction knows that he will be compared with that in another. If there is a positive correlation in the cost shocks, then this creates an informational externality. However, unlike the pure transparency model, studying this requires a model of equilibrium behavior generating information, i.e., equilibrium in both jurisdictions.

To extend the model to include yardstick comparisons, suppose now that here are two identical jurisdictions, labeled "domestic" and "foreign"; variables that apply to the foreign jurisdiction will be denoted by the prime symbol. To focus on symmetric equilibria of the game among incumbents and voters in the two jurisdictions, assume that the joint probability distribution function of cost shocks $\operatorname{Pr}\left(\theta, \theta^{\prime}\right)$ is symmetric, with

$$
\begin{aligned}
& \operatorname{Pr}(H, H)=\operatorname{Pr}(L, L)=\frac{\rho}{2} \\
& \operatorname{Pr}(H, L)=\operatorname{Pr}(L, H)=\frac{1-\rho}{2}
\end{aligned}
$$

Moreover, we work with the case where $\rho>1 / 2$, so that cost shocks in the two jurisdictions are positively correlated. To further simplify the analysis, we assume that $\hat{s}>(1-\beta) X$, so that a separating equilibrium cannot exist. Since the marginal p.d.f. has $q=\operatorname{Pr}(\theta=H)=1 / 2$, it follows from Lemma 1 that the unique equilibrium of the game without yardstick competition is one with pooling. We now show that, depending on the value of $\pi$, both hybrid and pooling equilibria are possible with yardstick competition.

When performance of foreign as well as domestic officials is observable, voters may base their decision to re-elect the incumbent or not on relative performance in the two jurisdictions. Voters will now condition their voting behavior on tax setting in both the domestic and foreign jurisdictions. Accordingly, let the probability of re-election in the domestic jurisdiction be $\sigma\left(x, x^{\prime}\right)$ when observed spending levels in the domestic and foreign jurisdictions are $x$ and $x^{\prime}$ respectively. We say the voter's strategy involves yardstick

\footnotetext{
${ }^{14}$ Holmstrom (1982) gives the classic treatment in an agency model. Meyer and Vickers (1997) consider these issues in a model of regulation a context in which yardstick competition is widely used.
} 
competition when re-election occurs with positive probability if spending is high in both jurisdictions, but the probability of re-election is zero if domestic spending is high and foreign spending is low. That is, a re-election rule with yardstick competition has $\sigma\left(x_{H}, x_{H}\right)=\sigma$ for some $\sigma>0$ and $\sigma\left(x_{H}, x_{L}\right)=0 .^{15}$

As before, let $\lambda$ denote the probability type $(b, L)$ chooses $s_{1}=\hat{s}$. Since we look for an equilibrium in which the strategies adopted by domestic and foreign incumbents are symmetric $\left(\lambda=\lambda^{\prime}\right)$, the p.d.f. $\operatorname{Pr}\left(x, x^{\prime} \mid i\right)$ of domestic and foreign spending conditional on type of the domestic politician can be calculated as

$$
\begin{aligned}
& \operatorname{Pr}\left(x_{H}, x_{H} \mid g\right)=\pi \frac{\rho}{2}+(1-\pi) \lambda \frac{1-\rho}{2} \\
& \operatorname{Pr}\left(x_{H}, x_{H} \mid b\right)=\pi \lambda \frac{1-\rho}{2}+(1-\pi) \lambda^{2} \frac{\rho}{2}
\end{aligned}
$$

(There are two terms in each probability because $x^{\prime}=x_{H}$ might have been generated by a good foreign politician facing high costs or a bad foreign politician facing low costs.) Voters' posterior beliefs about the incumbent can therefore be calculated from Bayes' rule:

$$
\begin{aligned}
\operatorname{Pr}\left(g \mid x_{H}, x_{H}\right) & =\frac{\pi}{\pi+(1-\pi) \ell(\lambda, \rho, \pi)} \\
\ell(\lambda, \rho, \pi) & =\frac{\operatorname{Pr}\left(x_{H}, x_{H} \mid b\right)}{\operatorname{Pr}\left(x_{H}, x_{H} \mid g\right)}
\end{aligned}
$$

where $\ell(\lambda, \rho, \pi)$ is the likelihood ratio that $\left(x_{H}, x_{H}\right)$ was generated by a bad rather than good incumbent. Key to understanding the logic of the ensuing results in the fact that $\ell(\cdot)$ is a decreasing function of $\pi$ - the worse the initial reputation of the incumbent, the more likely it is that $\left(x_{H}, x_{H}\right)$ was generated by a bad incumbent. This is because, at low $\pi,\left(x_{H}, x_{H}\right)$ is more likely generated by a foreign bad incumbent with cost of $L$ than a foreign good incumbent with a cost of $H$. But with positive correlation in costs, it is also more likely that the cost at home is $L$ and hence that the domestic incumbent is bad.

A necessary and sufficient condition for an equilibrium with yardstick competition to exist is that $\operatorname{Pr}\left(g \mid x_{H}, x_{L}\right)<\pi$, so that the voter prefers to

\footnotetext{
${ }^{15}$ Of course, $\sigma\left(x_{L}, x^{\prime}\right)=1$ in equilibrium for all $x^{\prime}$, as in the unilateral model of Section 3.
} 
remove the incumbent from office when domestic spending is high and foreign spending is low. Moreover, the equilibrium is pooling if $\operatorname{Pr}\left(g \mid x_{H}, x_{H}\right)>\pi$ for $\lambda=1$, and is hybrid otherwise. After some tedious manipulation, these conditions reduce to a simple one, given in the following result.

Lemma 6 Suppose that $\hat{s}(\mu)>(1-\beta) X$. Then voters use yardstick competition in equilibrium. A pooling equilibrium exists if and only if $\pi \geq 1 / 2$, and a hybrid equilibrium exists if and only if $\pi<1 / 2$.

To interpret this, recall that, in the absence of yardstick comparisons, the equilibrium would have bad incumbents choosing $x_{H}$ when the state is $\theta=L$, yielding a pooling equilibrium. Compared to this benchmark, the case of yardstick competition deviates in three ways. First, a bad domestic incumbent may not be re-elected when he chooses $x_{H}$, if the foreign incumbent is good and gets a low cost draw. Second, a good domestic incumbent is retained in office when costs are high, and the foreign politician chooses maximal rents. These changes to the voter's strategy reflect the clear-cut information advantage from yardstick competition. Third, pooling may no longer be optimal for incumbents when the foreign incumbent has a poor initial reputation. To see this, observe that the likelihood ratio $\ell(\lambda, \rho, \pi)$ is decreasing in $\pi$, as it depends on the voter's assessment of the quality of the incumbent in the other jurisdiction. Thus facing a foreign incumbent with a low reputation makes it relatively less likely that the $\left(x_{H}, x_{H}\right)$ outcome is generated by a good domestic incumbent, and hence that voters will re-elect an incumbent who picks $x_{H}$. The equilibrium now has the bad incumbent reducing the probability that he chooses $\hat{s}$ in order to raise the signaling value of the outcome $x_{H}$. A foreign incumbent with a poor reputation inflicts a reputational externality on a domestic bad incumbent and reduces his incentive to pool with a good incumbent. Moreover, this aspect of yardstick competition increases rent seeking.

Since improved information available through yardstick comparisons has countervailing effects on incentives and selection of politicians, its net impact on voter welfare is unclear. The following result shows that the reputations of politicians are key to understanding this.

Proposition 7 There exist parameters $0<\tilde{\pi}_{a}<\tilde{\pi}_{b}<1 / 2$ such that voter welfare is lower when yardstick comparisons are available than when they are not if $\pi<\tilde{\pi}_{a}$, and the converse is true if $\pi>\tilde{\pi}_{b}$. 
This result emphasizes that voters who are better informed about the fiscal environment may be worse off in equilibrium, as bad politicians put less effort into building a reputation when they first take office. This insight explains the above result. In some circumstances ( $\pi$ low), voters would be better off if they could commit to ignoring the fiscal performance in the other jurisdiction in the course of a domestic election.

Yardstick competition is welfare decreasing when politicians' reputations are poor because rents are increased with little advantage from the improved information generated as most politicians who are kicked out are replaced by an incumbent of the same type.

\section{Concluding Remarks}

A key issue in political economy concerns whether ideas from the Pigouvian view of benevolent government are relevant when politics are introduced to the model. One important dimension of this concerns whether government is likely to act in the interests of the electorate. However, this cannot be resolved by assumption - it depends on the way in which re-election incentives work in holding government to account. We have set up a simple model that nests two extreme views of government. The fact that government is imperfect gives a prima facie role for fiscal restraints. Whether fiscal restraints are in fact desirable depends on the balance of selection and discipline effects in politics.

The model of elections used here is quite specific. However, it is a natural framework to use in addressing these issues. Any failures in the political process are due to limited information and incompleteness in contracts. It remains to be seen how far the insights obtained here carry over to other models of political resource allocation. ${ }^{16}$

Among the most surprising findings is that certain kinds of fiscal restraint are more likely to be a good idea for voters, the closer is politics to the benevolent government ideal. However, this conclusion was shown to vary by the type of restraint being considered. Thus, the analysis stresses the need to think about each type of restraint on its merits. In moving forward, the model has empirical implications tying together electoral accountability, policy choices, and public finance.

\footnotetext{
${ }^{16}$ See Besley (2003), chapter one, for further discussion on this.
} 
The kind of piecemeal institutional analysis conducted here is a useful way of addressing some policy issues. But the analysis does not address the form of optimal fiscal constitutions. We take it as a binding constraint on a democratic system that leaders must face periodic elections rather than looking for optimal incentive contracts. Exploring the form of optimal constitutions in a situation of limited information presents a challenging agenda for future research. ${ }^{17}$

\footnotetext{
${ }^{17}$ For discussion in this direction, see Laffont (2000).
} 


\section{References}

[1] Alt, James E., and David Dreyer Lassen [2003], "Fiscal Transparency and Fiscal Policy Outcomes in OECD Countries," unpublished typescript.

[2] Barro, Robert J., [1973], "The control of politicians: An economic model," Public Choice, 14, 19-42.

[3] Becker, Gary S. and Casey B. Mulligan, [1998], "Deadweight costs and the size of government," NBER Working Paper No. 6789.

[4] Besley, Timothy J., [2003], Principled Agents? Motivation and Incentives in Government, The Lindahl Lectures 2002, forthcoming from Oxford University Press.

[5] Besley, Timothy J. and Anne C. Case, [1995a], "Incumbent Behavior: Vote Seeking, Tax Setting and Yardstick Competition", American Economic Review 85(1), 25-45.

[6] Besley, Timothy J. and Anne C. Case, [1995b], "Does Political Accountability Affect Economic Policy Choices? Evidence From Gubernatorial Term Limits," Quarterly Journal of Economics 110(3), 769-98.

[7] Bodenstein, Martin and Heinrich Ursprung, [2001], "Political Yardstick Competition, Economic Integration, and Constitutional Choice in a Federation," CESifo Working Paper No. 501.

[8] Bordignon, Massimo, Floriana Cerniglia and Federico Revelli, [2001], "In search of yardstick competition: Property tax rates and electoral behavior in Italian cities ," typescript.

[9] Brennan, Geoffrey and James M. Buchanan, [1980], The Power to Tax: Analytical Foundations of a Fiscal Constitution, Cambridge: Cambridge University Press.

[10] Brueckner, Jan J., [2000], "Strategic Interaction Among Governments: An Overview of Empirical Studies," unpublished typescript, University of Illinois. 
[11] Buchanan, James, [1967], Public Finance in Democratic Process: Fiscal Institutions and Individual Choice, Durham, NC: University of North Carolina Press.

[12] Buchanan, James, [1989], "The Public Choice Approach," in Explorations into Constitutional Economics, Texas A\&M University Press.

[13] Buchanan, James and Roger Congleton, [1979], "Proportional and progressive income taxation with utility-maximizing governments," Public Choice, 34(1), 217-230.

[14] Coate, Stephen and Stephen Morris, [1995], "On the form of transfers to special interests," Journal of Political Economy, 105, 1210-1235.

[15] Dewatripont, Mathias, Ian Jewitt and Jean Tirole, [1999], "The Economics of Career Concerns," Review of Economic Studies, 66(1), 189217.

[16] Edwards, Jeremy and Michael Keen, [1996], "Tax competition and Leviathan," European Economic Review, 40, 113-134.

[17] Ferejohn, John, [1986], "Incumbent performance and electoral control," Public Choice, 50, 5-25.

[18] Fischer, Stanley and Lawrence H. Summers, [1989], "Should governments learn to live with inflation?", American Economic Review, 79(2), $382-87$.

[19] Hindriks, Jean and Paul, Belleflamme, [2001], "Yardstick Competition and Political Agency Problems," Queen Mary and Westfield College, Department of Economics Discussion Papers, No. 444, available at http://www.econ.qmw.ac.uk/papers/wp444.htm.

[20] Holmstrom, Bengt, [1979], "Moral Hazard and Observability," Bell Journal of Economics and Management Science, 10(1), 74-91.

[21] Holmstrom, Bengt, [1982], "Moral Hazard in Teams", Bell Journal of Economics and Management Science, 13(2), 324-40.

[22] Krusell, Per, Vincenzo Quadrini, Jose-Victor Rios-Rull, [1996], "Are consumption taxes really better than income taxes," Journal of Monetary Economics, 37(3), 475-503. 
[23] Laffont, Jean-Jacques, [2000], Incentives and Political Economy, Oxford: Oxford University Press.

[24] Meyer, Margaret A. and John S. Vickers, [1997], "Performance comparisons and dynamic incentives," Journal of Political Economy, 105, $547-581$.

[25] North, Douglass C., [1985], "The growth of government in the United States: An economic historian's perspective," Journal of Public Economics, 28, 383-99.

[26] Organization for Economic Cooperation and Development, [1998], "Harmful Tax Competition: An Emerging Global Issue," Paris.

[27] Peltzman, Sam, [1980], "The growth of government," Journal of Law and Economics, 23(2), 209-87.

[28] Peltzman, Sam, [1992], "Voters as Fiscal Conservatives," Quarterly Journal of Economics, 107(2), 327-61.

[29] Pigou, Arthur C., [1920], The Economics of Welfare, First Edition, London: MacMillan.

[30] Poterba, James M. and Jurgen M. von Hagen, [1999], (eds) Fiscal Institutions and Fiscal Performance, Chicago: Chicago University Press.

[31] Prat, Andrea, [2002], "The Wrong Kind of Transparency" typescript.

[32] Rueben, Kim [1997], "Tax Limitations and Government Growth: The Effect of State Tax and Expenditure Limits on State and Local Government," typescript.

[33] Revelli, Federico, [2001], "Local Taxes, National Politics and Spatial Interactions in English District Election Results," forthcoming in European Journal of Political Economy.

[34] Schaltegger, Christoph A. and Dominique Küttel, [2001], "Exit, voice, and mimicking behavior: Evidence from Swiss cantons," typescript.

[35] Salmon, Pierre, [1987], "Decentralization as an Incentive Scheme," $O x$ ford Review of Economic Policy, 3(2), 24-43. 
[36] Strumpf, Koleman, [2000], "Does Decentralization Increase Policy Innovation?" typescript

[37] Wilson, John D., [1999], "Theories of Tax Competition," National Tax Journal, 52(2), 269-304.

[38] Wilson, John, D., [2000], "Welfare Improving Competition for Mobile Capital," typescript. 


\section{Appendix A: Proofs of Results}

Proof of Lemma 1: Here we prove the "if" part of the lemma; the converse can be verified by substitution. Suppose that (4) holds. Then $\hat{s}+\beta \sigma X \leq X$ for all $\sigma \leq 1$, so that $\lambda=0$ is a best response. When $\lambda=0, \operatorname{Pr}\left(g \mid x_{H}, x_{H}\right)=1$ and voters strictly prefer to re-elect the incumbent when spending is high. This establishes part 3 of the result.

When $q \geq 1 / 2$, then $\operatorname{Pr}\left(g \mid x_{H}\right) \geq \pi$ for all $\lambda \leq 1$, implying $\sigma=1$ is a best response for voters. When (4) does not hold, then $\lambda=1$ so that only a pooling equilibrium exists. This establishes part 2. When $q<1 / 2, \operatorname{Pr}\left(g \mid x_{H}\right)<\pi$ for $\lambda=1$ (so a pooling equilibrium cannot exist) but $\operatorname{Pr}\left(g \mid x_{H}\right)=\pi$ when $\lambda=q /(1-q)<1$. A strictly mixed strategy for type $(b, L)$ is a best response if and only if $\hat{s}+\beta \sigma X=X$, which establishes part 2 .

\section{Proof of Proposition 1:}

$$
\begin{aligned}
\frac{\partial E W}{\partial \mu}= & q\left[(1+\beta)+\lambda \frac{1-q}{q}(1-\pi)\right] \frac{\partial W^{g}(H, \mu)}{\partial \mu} \\
& +(1-q)[(1+\beta)-\lambda(1-\pi)] \frac{\partial W^{g}(L, \mu)}{\partial \mu}
\end{aligned}
$$

which is negative since $\partial W_{g}^{*}(\theta, \mu) / \partial \mu<0$ and $\lambda \leq 1$.

Proof of Proposition 2: The only two possible changes in equilibrium strategy are from a pooling equilibrium to a separating equilibrium or from a hybrid equilibrium to a separating equilibrium. As in the text define $\underline{\mu}$ from $s(\underline{\mu})=(1-\beta) X$. From Proposition 1, we know that welfare is decreasing locally along the path to $\mu$. For $\mu>\mu$, welfare will be at its full information value. We now make use of the following result and its corollary.

Lemma 8 Expected welfare of voters is weakly greater in equilibrium when unit $\operatorname{cost} \theta$ is unobserved than in the full information case if and only if the discipline effect outweighs the selection effect, viz. if and only if $D(\mu) \geq$ $\beta \pi S(\mu)$.

Proof of Lemma 8: When voters have full information about $\theta$, the equilibrium outcome is identical to that of the separating equilibrium. Using (5), it is possible to calculate expected welfare for each of the three equilibrium configurations. In the pooling equilibrium,

$$
E W^{p}=(1+\beta) E W^{0}+(1-\pi)(1-q) D(\mu)+\beta \pi(1-\pi) q S(\mu)
$$


while in the hybrid equilibrium,

$$
E W^{h}=(1+\beta) E W^{0}+(1-\pi) q D(\mu)+\beta \pi(1-\pi)(1-q) S(\mu)
$$

and in the separating (or full-information) equilibrium,

$$
E W^{s}=(1+\beta) E W^{0}+\beta \pi(1-\pi) S(\mu)
$$

The change in equilibrium welfare due to imperfect information is therefore, for the pooling equilibrium,

$$
E W^{p}-E W^{s}=(1-\pi)(1-q)[D(\mu)-\beta \pi S(\mu)]
$$

and, for the hybrid equilibrium,

$$
E W^{h}-E W^{s}=(1-\pi) q[D(\mu)-\beta \pi S(\mu)]
$$

Comparison of these expressions yields the result.

We now prove the Proposition. Let $\pi^{*}$ solve $D=\beta \pi^{*} S$ and note $S>$ $D>0$ implies $\pi^{*}>0$ and $\pi^{*}<1$ if $\beta$ is sufficiently large. If $\pi>\pi^{*}$, then the improvement in information reinforces that in Proposition 1 and welfare must be globally decreasing in $\mu$. However, if $\pi \leq \pi^{*}$, then there is discontinuous increase in welfare around $\mu$. Thus in a neighborhood of $\mu$, voter welfare is increasing which justifies the second claim.

Proof of Proposition 3: Let $\kappa$ be the limit on government spending and denote equilibrium welfare by $E W(\lambda, \sigma, \mu, \kappa)$. Suppose that $\kappa \geq x_{L}$. The effect of reducing the spending limit for any fixed equilibrium strategies $(\lambda, \sigma)$ is

$-\frac{\partial E W(\lambda, \sigma, \mu, \kappa)}{\partial \kappa}=-(1-\pi) \mu C^{\prime}(\kappa)[(1-q) \lambda-1+\beta(\pi(q \sigma+(1-q)(1-\sigma \lambda))-1)]>0$.

When equilibrium strategies change in response to a change in $\kappa$, voter welfare changes discontinuously, with a move from separating to pooling equilibrium as $\kappa$ becomes sufficiently small. Denote the critical value by $\hat{\kappa}$ satisfying $\hat{s}(\mu)=(1-\beta) \hat{\kappa}$, and assume $\hat{\kappa} \geq x_{L}$. Define $\hat{\pi}(\hat{\kappa})$ from $D(\hat{\kappa}, \mu)=\beta \hat{\pi}(\hat{\kappa}) S(\hat{\kappa}, \mu)$. Now observe that, provided that $\pi<\hat{\pi}(\hat{\kappa})$, welfare will be decreasing in $\kappa$ at the point of discontinuity $\hat{\kappa}$ (using the argument of Lemma A3). Thus, for small enough $\pi$, welfare is increasing in the tax limitation $\kappa$ for any $\kappa \geq x_{L}$. 
Proof of Lemma 2: A pooling equilibrium exists if and only if $\operatorname{Pr}\left(g \mid x_{H}, x_{H}\right) \geq$ $\pi$ when $\lambda=1$ or, recalling (11), if and only if $\ell(1, \rho, \pi) \leq 1$. From the definitions of the conditional probabilities, this in turn holds if and only if

$$
(1-\pi) \rho+\pi(1-\rho) \leq(1-\pi)(1-\rho)+\pi \rho
$$

which, since $\rho>1 / 2$, simplifies to $\pi \geq 1 / 2$.

It remains to be determined whether voters choose to re-elect the incumbent when $\left(x, x^{\prime}\right)=\left(x_{H}, x_{L}\right)$ or not. (Only in the latter case does an equilibrium with yardstick competition exist.) At this information set, the posterior probability the incumbent is the good type is

$$
\operatorname{Pr}\left(g \mid x_{H}, x_{L}\right)=\frac{\pi}{\pi+(1-\pi) \rho \lambda /(1-\rho)}
$$

Hence $\operatorname{Pr}\left(g \mid x_{H}, x_{L}\right)<\pi$ if and only if $\lambda>(1-\rho) / \rho$. It is immediate this holds in the pooling equilibrium (when $\pi \geq 1 / 2$ ) since $\rho>1 / 2$. It can also be established the inequality holds in the hybrid equilibrium (when $\pi<1 / 2$ ). To see this, observe that

$$
\ell_{\lambda}(\lambda, \rho, \pi)=\frac{\ell}{\lambda}+\frac{\lambda}{\left[\operatorname{Pr}\left(x_{H}, x_{H} \mid g\right)\right]^{2}} \pi(1-\pi)\left[\rho^{2}-(1-\rho)^{2}\right]>0
$$

since $\rho>1 / 2$. Thus, since $\ell\left(\lambda^{*}, \rho, \pi\right)=1$ and

$$
\ell((1-\rho) / \rho, \rho, \pi)=\frac{1}{(1-\pi)+\pi \rho^{2} /(1-\rho)^{2}}<1
$$

for $\rho>1 / 2$, we must have $\lambda^{*}>(1-\rho) / \rho$. Hence voters remove the incumbent from office when $\left(x, x^{\prime}\right)=\left(x_{H}, x_{L}\right)$ for all values of $\pi$.

Proof of Proposition 7: Analogous to (5), expected welfare of voters for any equilibrium $(\lambda, \sigma)$ is given by:

$$
E W(\lambda, \sigma, \rho)=(1+\beta) E W^{0}+\frac{1-\pi}{2} \lambda D+\beta\left(\pi_{2}-\pi\right) S
$$

where $S>D>0$ are defined as before. In this expression, the second term represents the discipline effect of elections: with probability $(1-\pi) \lambda / 2$, the incumbent is type $(b, L)$ and chooses $s_{1}=\hat{s}$ instead of $s_{1}=X$. The third term in the expression is the selection effect of elections. Recall that the 
voter re-elects when $x=x_{L}$ (which occurs with probability $\pi / 2$ ) and reelects with probability $\sigma$ when $\left(x, x^{\prime}\right)=\left(x_{H}, x_{H}\right)$. Further, the incumbent is re-elected in state $\left(x_{H}, X\right)$ if $\operatorname{Pr}\left(g \mid x_{H}, X\right)>\pi$. The challenger is elected with complementary probability, in which case the posterior probability the second-period incumbent is good is $\pi$. Thus $\pi_{2}$, the probability that a good politician is in office during the second period, satisfies

$$
\begin{aligned}
\pi_{2}=\frac{\pi}{2}+\left(1-\frac{\pi}{2}\right) \pi & +\pi(1-\pi) \sigma\left(\operatorname{Pr}\left(x_{H}, x_{H} \mid g\right)-\operatorname{Pr}\left(x_{H}, x_{H} \mid b\right)\right) \\
& +\pi(1-\pi) \max \left\{\operatorname{Pr}\left(x_{H}, X \mid g\right)-\operatorname{Pr}\left(x_{H}, X \mid b\right), 0\right\}
\end{aligned}
$$

The conditional probabilities in state $\left(x_{H}, x_{H}\right)$ are defined in (10). Analogously, the conditional probabilities of $\left(x_{H}, X\right)$ are:

$$
\begin{aligned}
& \operatorname{Pr}\left(x_{H}, X \mid g\right)=(1-\pi)\left(\frac{\rho}{2}+\frac{1-\rho}{2}(1-\lambda)\right) \\
& \operatorname{Pr}\left(x_{H}, X \mid b\right)=(1-\pi)\left(\frac{\rho}{2}(1-\lambda) \lambda+\frac{1-\rho}{2} \lambda\right)
\end{aligned}
$$

In the absence of yardstick information, the equilibrium is pooling $(\lambda=1)$ and the probability a good official is in office in the second period is

$$
\pi_{2}^{n y}=\pi+\frac{1}{2} \pi(1-\pi)
$$

whereas, in the equilibrium with yardstick competition, (20) simplifies to

$$
\begin{aligned}
& \pi_{2}^{y}=\pi_{2}^{n y}+\pi^{2}(1-\pi)\left(\rho-\frac{1}{2}\right) \\
& \pi_{2}^{y}=\pi_{2}^{n y}+\frac{1}{2} \pi(1-\pi)^{2} \max \left\{1-(2-\rho) \lambda+\rho \lambda^{2}, 0\right\}
\end{aligned}
$$

if the equilibrium is hybrid. The difference in equilibrium welfare in the two cases is

$$
\Delta=E W^{y}-E W^{n y}=(\lambda-1) \frac{1-\pi}{2} D+\left(\pi_{2}^{y}-\pi_{2}^{n y}\right) \beta S
$$

In the pooling equilibrium, which exists if $\pi \geq 1 / 2, \lambda=1$, so that $\Delta>0$. In the hybrid equilibrium, we have $\lambda<1$ and $\pi_{2}^{y} \geq \pi_{2}^{n y}$, so that the first term in the expression is negative and the second is non-negative. When $\pi=0$, however, $\pi_{2}^{y}=\pi_{2}^{n y}=0$, so that $\Delta<0$. Since $\Delta$ is continuous in $\pi$, the result follows. 